\title{
The effect of the new GMS contract on GP appointment provision in Wales: postal questionnaire survey of practice managers Andrea Edwards ${ }^{1}$ and Richard D Neal*2
}

\author{
Address: 'Victoria Gardens Surgery, Victoria Gardens, Neath, West Glamorgan, SA11 3AY, UK and ${ }^{2}$ Department of Primary Care \& Public Health \\ School of Medicine/North Wales Clinical School, Gwenfro Unit 5, Wrexham Technology Park, Wrexham, LL13 7YP, UK \\ Email: Andrea Edwards - andrea.edwards@gp-w98036.wales.nhs.uk; Richard D Neal* - nealrd@cf.ac.uk \\ * Corresponding author \\ Published: 24 November 2008 \\ BMC Research Notes 2008, I:II7 doi:10.1 186/1756-0500-I-II7 \\ Received: 12 November 2008 \\ Accepted: 24 November 2008 \\ This article is available from: http://www.biomedcentral.com/I756-0500/I/II7 \\ (C) 2008 Neal et al; licensee BioMed Central Ltd. \\ This is an Open Access article distributed under the terms of the Creative Commons Attribution License (http://creativecommons.org/licenses/by/2.0), \\ which permits unrestricted use, distribution, and reproduction in any medium, provided the original work is properly cited.
}

\begin{abstract}
Background: Access to health professionals is a key UK NHS priority, and meeting access targets is rewarded through the new General Medical Services (GMS) contract in the UK. We sought to determine the current state of appointment provision in Wales and any changes resulting from the need to meet indicators in the new GMS contract. We undertook a postal questionnaire study of practice managers in all general practices in Wales.
\end{abstract}

Findings: Valid responses were received from 396/505 (78.4\%) practice managers. 36I (93.1\%) practices reported that they had achieved the target for 2004/05. 104 (26\%) practices reported that they were 100\% open access/advanced access. The most frequent changes reported in response to the new GMS contract were offering more open or advanced access slots $(237,60 \%)$, more GP phone consultations $(167,42 \%)$, introducing a telephone triage system $(100,25 \%)$, introducing a minor illness clinic (76, 19\%), and employing or training a nurse practitioner (59, 15\%). 83\% practice managers believed that patients were able to get an appointment at the time they need it either 'all of the time' or 'most of the time', and $70 \%$ that patients were able to get an appointment with the GP of choice either 'all of the time' or 'most of the time'.

Conclusion: This survey has demonstrated the current extent of appointment provision in Wales, and how changes have been driven by incentives. Whether these changes are in the best interests of either patients or doctors, or both, remains to be seen.

\section{Background}

Access to primary care professionals is a key NHS priority, $[1]$ and there is increasing evidence that patients value improved access to primary care.[2] In Wales, an objective for the next decade stated in 2001 was to promote universal and faster access to services,[3] and an important Welsh Assembly Government policy document outlined the following target: 'patients will be able to access an appropriate member of the primary care team within 24 hours of requesting an appointment and much sooner in an emergency'.[4]

Over the past few years, many practices have adopted either a complete open access or advanced access $[5,6]$ model of appointment provision. Open access is usually taken to mean regular surgeries that are not bookable in advance and are often run in combination with booked appointments. Advanced Access is an approach to 
appointment systems based on measuring and predicting demand each day and matching capacity to demand so that patients can book on the day of their choice. [7] However many practices that purport to use Advanced Access do not use the model's key principles.[8] However there remains contention about the relative advantages and disadvantages, as assessed in different ways from different perspectives, to these systems, especially for certain groups of patients. [9-13] There has been a range of other initiatives aimed at improving access generally. These include: telephone consultations; telephone triage; nurse led minor illness clinics; and the introduction of nurse practitioners and health care assistants, however the evidence for their widespread use remains contentious.

The new General Medical Services (nGMS) contract for general practice was introduced in 2003.[14] The nGMS contract includes financial incentives to practices that achieve an access target; through both the Quality and Outcomes Framework (QoF) (50 bonus points), and the enhanced service category, which differs in each of the four UK countries. Practices in Wales submit an annual plan to their LHB outlining their intention to improve patient access to services. These individual, practice-based plans are then agreed and monitored, and funding of $£ 5000$ per average practice size paid. Each LHB has a responsibility to carry out validation checks to ensure that information provided by practices is correct.

We sought to determine the current state of appointment provision in Wales and any changes resulting from the need to meet indicators in the nGMS contract. We were keen to compare the experience in Wales to that of demonstrated by surveys in England and Northern Ireland. $[8,15]$ We undertook this by asking practice managers to answer a brief questionnaire about access in their own practices. We believe that this is of international importance given the variation in the provision of access and in the use of incentives to change practice systems.

\section{Methods}

We conducted a postal questionnaire survey of all practice managers in Wales. We developed and piloted a structured questionnaire that asked questions about the current appointment provision, changes since the nGMC contract, complaints and aggression, their own opinion and their opinion of others' views of the appointment provision, and factual data about the practice. Questions and response options were amended after piloting. Items in the final questionnaire are shown in Table 1.

As far as was possible, we used strategies demonstrated in a recent systematic review to maximize response; [16] these included one sheet of double-sided A4 paper only, individualized letters, handwritten envelopes, second class stamped return envelopes, and a reminder to nonresponders.

Practice managers were identified from LHB lists and sent the questionnaire with a covering letter and a stamped return envelope in April 2006. Initial non-responders were sent a reminder with a further questionnaire and return envelope one month later.

Data were entered into an Excel spreadsheet. Data entry checks were made on every tenth record. Analysis was undertaken in Excel, and using SPSS. In order to determine whether open/advanced access and QoF target achievement was associated with practice size, $\mathrm{t}$-tests were undertaken.

Given funding and resource limitations we were unable to undertake any validation of the questionnaire responses against other sources of data.

\section{Results}

\section{Response}

From a sample of 505 practice managers, there were a total of $396(78.4 \%)$ valid responses.

\section{Practice size and personnel}

The mean and median numbers of patients per practice were 6459 and 6180 . The mean and median numbers of patients per whole-time GP were 1863 and 1857. The mean number of GPs per practice was 3.05. The mean number of nurses, health care assistants and nurse practitioners being $1.68,0.57$ and 0.29 .245 practices employed healthcare assistants ranging from 0.10 - 3.3 WTE. 94 practices employed nurse practitioners ranging from 0.30-3.5 WTE.

\section{Quality and Outcomes Framework (QoF) access target}

$361(93.1 \%)$ practices reported that they had achieved the target for 2004/05.

\section{Access to appointments}

$104(26 \%)$ practices reported that they were 100\% open access/advanced access, with 292 (74\%) stating that they were not. Of the practices that were not, 231 (79\%) offered 'same day' appointments, 204 (70\%) 'the next working day', 206 (70\%) 'up to two working days or more in advance', $238(81 \%)$ 'up to one week in advance', 175 $(60 \%)$ 'up to one month in advance', and $92(31 \%)$ 'more than one month in advance'. These categories were not mutually exclusive with responses covering the range of options that practices were able to offer.

\section{Significant changes made since nGMS contract}

In response to the question about changes made since the nGMS contract, offering more open or advanced access 
Table I: Items on questionnaire

Is your practice $100 \%$ open/advanced access? (Y/N)

If not, in a normal working week, does your practice offer pre-bookable appointments for:

The same day? (Y/N)

Next working day? (Y/N)

Up to two days or more in advance? (Y/N)

Up to one week in advance? (Y/N)

Up to one month in advance? (Y/N)

More than one month in advance? (Y/N)

Has your practice made any of the following significant changes to your appointment system, or the services offered to patients since the introduction of the nGMS contract?

Offered more open/advanced access or less bookable slots? (Y/N)

Introduced a telephone triage system for appointments? (Y/N)

Employed/trained a nurse practitioner? (Y/N)

Introduced a minor illness clinic? (Y/N)

More GP phone consultations on a systematic basis? (Y/N)

Factual data about the practice:

List size/Number of WTE doctors/nurse practitioners/nurses/healthcare assistants

Did your practice achieve the QoF Access Target 2004/2005? (Y/N)

In your opinion, are patients able to obtain an appointment at the time they need it?

Answer options: all of the time/most of the time/some of the time/not very often, hardly ever/don't know

In your opinion, do patients get an appointment with the GP of their choice?

Answer options: all of the time/most of the time/some of the time/not very often/hardly ever/don't know

In your opinion, what has happened to the number of verbal complaints received at the practice regarding the appointment system? Answer options: increased a lot/increased a little/stayed the same/decreased a little/decreased a lot

In your opinion, what has happened to the level of aggression directed at receptionists if patients don't get the appointment they want when they want it?

Answer options: increased a lot/increased a little/stayed the same/decreased a little/decreased a lot

In your opinion, from the perspective of GPs, do you think they consider the current system of appointment provision to be?

Answer options: very good/good/satisfactory/poor/very poor

In your opinion, from the perspective of receptionists, do you think they consider the current system of appointment provision to be?

Answer options: very good/good/satisfactory/poor/very poor

In your opinion, from the perspective of patients, do you think they consider the current system of appointment provision to be? Answer options: very good/good/satisfactory/poor/very poor

Table 2: Responses to questions about appointments at time of patient need and with doctor of choice

\begin{tabular}{|c|c|c|c|c|c|c|}
\hline & All of the time $(\%)$ & Most of the time (\%) & Some of the time (\%) & Not very often (\%) & Hardly ever (\%) & Don't know (\%) \\
\hline $\begin{array}{l}\text { Are patients able to } \\
\text { obtain an } \\
\text { appointment at the } \\
\text { time they need it? }\end{array}$ & $59(15)$ & $27 \mid(68)$ & $63(16)$ & $3(1)$ & $0(0)$ & $0(0)$ \\
\hline $\begin{array}{l}\text { Do patients get an } \\
\text { appointment with the } \\
\text { GP of their choice? }\end{array}$ & $55(14)$ & $223(56)$ & I I 5 (29) & $2(1)$ & I (0) & $0(0)$ \\
\hline
\end{tabular}


slots was the more frequent response, made by 237 $(60 \%)$. This was followed by 167 (42\%) respondents stating 'more GP phone consultations on a systematic basis', $100(25 \%)$ respondents stating 'introduced a telephone triage system for appointments', 76 (19\%) respondents 'introduced a minor illness clinic', and 59 (15\%) respondents 'employed/trained a nurse practitioner'.

\section{Appointments at time of patient need and with doctor of choice}

The responses to these two questions are summarized in Table 2. This shows that $83 \%$ of practice managers believed that patients were able to get an appointment at the time they need it either 'all of the time' or 'most of the time', and that $70 \%$ of practice managers believed patients were able to get an appointment with the GP of choice either 'all of the time' or 'most of the time'.

\section{Verbal complaints and aggression}

The responses to these two questions are summarized in Table 3. This shows the biggest response category for both questions was 'stayed the same', with $45 \%$ answering this for verbal complaints and $47 \%$ for aggression towards receptionists. There were slightly more responses for the 'decreased' options for both questions than the 'increased' options.

\section{Practice managers' views of how others regard the appointment system}

The last question asked practice managers, in their opinion, what other groups considered the current system of appointment provision to be like. These groups were GPs, receptionists, and patients. The findings are summarized in Table 4. This shows that whilst all three groups were perceived to rate their systems highly, there were differences between them, with patients' views, and to a lesser extent receptionists' views were perceived slightly less positive than GPs' views.

\section{Association of open or advanced access and QoF target achievement with practice size}

Open or advanced access was associated with smaller practice list size (mean difference 901, $\mathrm{t}=-2.32,95 \% \mathrm{CI}$ $1666,-137, \mathrm{p}=0.02)$. QoF target achievement was not associated with practice list size (mean difference $1212, \mathrm{t}$ $=-1.78,95 \%$ CI $-129,-2552, \mathrm{p}=0.08)$, although a much larger sample size would be needed to detect this.

\section{Discussion}

\section{Summary of main findings}

One quarter of practices were $100 \%$ open or advanced access. Of the others, four fifths offered same day appointments, three fifths up to one week in advance, and one third more than a month in advance. The commonest changes to appointment provision reported were more open access slots, and more systematic use of GP telephone consultations. A large majority of practice managers believed that their current systems enable patients to get an appointment at the time they need it, and with their GP of choice. Practice managers reported no changes in either verbal complaints or aggression relating to appointment provision. They perceived that GPs, receptionists and patients all regarded their appointment systems positively. Open or advanced access was associated with smaller practice list size.

\section{Strengths and weaknesses}

For a postal questionnaire study we achieved an excellent response rate, which was greater than the English survey (245/391, 63\%), [8] but lower than the Northern Irish survey (94\%), although this only had 59 respondents.[15] Contributory factors to this may have included: a topical and relevant subject, a short and well-designed question-

Table 3: Responses to the questions about verbal complaints and aggression

\begin{tabular}{|c|c|c|c|c|c|c|}
\hline & Increased a lot (\%) & $\begin{array}{c}\text { Increased a little } \\
(\%)\end{array}$ & $\begin{array}{l}\text { Stayed the same } \\
\text { (\%) }\end{array}$ & $\begin{array}{c}\text { Decreased a little } \\
(\%)\end{array}$ & $\begin{array}{c}\text { Decreased a lot } \\
(\%)\end{array}$ & Don't know (\%) \\
\hline $\begin{array}{l}\text { What has happened } \\
\text { to the number of } \\
\text { verbal complaints } \\
\text { received at the } \\
\text { practice regarding } \\
\text { the appointment } \\
\text { system? }\end{array}$ & II (3) & $69(17)$ & $179(45)$ & $71(18)$ & $65(17)$ & $\mathrm{I}(0.2)$ \\
\hline $\begin{array}{l}\text { What has happened } \\
\text { to the level of } \\
\text { aggression directed } \\
\text { at receptionists if } \\
\text { patients don't get the } \\
\text { appointment they } \\
\text { want when they want } \\
\text { it? }\end{array}$ & $21(5)$ & $79(20)$ & $187(47)$ & $58(15)$ & $49(13)$ & $2(0.5)$ \\
\hline
\end{tabular}


Table 4: Practice managers' views of how others regard the appointment system

\begin{tabular}{lccccc}
\hline $\begin{array}{l}\text { Practice managers' view of how others regard their current system of } \\
\text { appointment provision }\end{array}$ & Very good (\%) & Good (\%) & Satisfactory (\%) & Poor (\%) & Very poor (\%) \\
\hline GP perspective & $136(34)$ & $164(41)$ & $80(20)$ & $16(4)$ & $0(0)$ \\
Receptionist perspective & $125(31)$ & $140(35)$ & $92(23)$ & $37(9)$ & $2(1)$ \\
Patient perspective & $82(21)$ & $164(41)$ & $121(31)$ & $27(7)$ & $2(1)$ \\
\hline
\end{tabular}

naire; the fact that practice managers are rarely consulted in research studies of this nature; and the questionnaire coming from a fellow practice manager. The list size per practice and per GP are in keeping with other data from Wales, and the sample responding to the questionnaire was similar in these respects to practices in Wales overall. Data from the MDSi Contract Manager database http:// www.msdinformatics.com/ClinPCT.htm reported that $92.8 \%$ of practices in Wales achieved the access bonus. This figure is very close to the data reported here, again suggesting that the sample responding to the questionnaire was similar in these respects to practices in Wales overall. The weaknesses are those of any questionnaire: we were limited to fixed response options, and had to assume a certain truth in the responses, taking the results at face value. We also cannot be sure that there is no systematic bias from the non-responders. Lastly, this was only a survey of practice managers and was not therefore able to address the view of patients or other health professionals. Their view may differ considerably. One of our questions (question 2), was, in retrospect, slightly ambiguous, and the findings from this question must be interpreted with additional caution. Additionally the wording of 'open' and 'advanced' access may have caused some confusion.

\section{Conclusion/discussion of the findings within the context of the literature}

This questionnaire survey has demonstrated the current extent of appointment provision in general practices in Wales and changes that have occurred since the implementation of the nGMS contract. The contract has led to a move towards more open/advanced access appointments and more telephone consulting. Whilst this may help practices achieve QoF access targets, its effect on the overall quality provision of general practice remains unknown. The effect of incentives on changing appointment provision has been demonstrated, and is similar to the findings from Northern Ireland.[15] The level of access to appointments in general practices in Wales, and the views of practice managers have been demonstrated. There is an issue about who access best serves: the patient or the practice, and the trade off between faster access and quality of care (e.g. longer consultations and reduced continuity of care).[12,13] There is also an issue about whether patients actually get appointments when they need rather than want them, and whether they are with their doctor of choice. For example working patients and those with complex chronic conditions may express a clear preference for pre-bookable appointments rather than faster access. This issue has not been resolved by the nGMS contract. It may be that some practices are choosing not to fully achieve the access target because they feel it is neither in their, nor their patients' best interests.

\section{Competing interests}

The authors declare that they have no competing interests.

\section{Authors' contributions}

The original idea for the study came from AE. RDN and AE jointly designed the study. AE undertook the fieldwork and conducted the analysis. RDN wrote the first draft of the paper. Both authors contributed to the final draft of the paper.

\section{Acknowledgements}

This work was completed as part of Andrea Edwards' dissertation for the Masters in Primary Care at the University of Wales. We would like to thank all of the practice managers who responded to the survey, and Jim Turner for statistical advice.

\section{References}

I. Department of Health: The NHS Plan. A plan for investment, a plan for reform. London: HMSO; 2000.

2. Welsh Assembly Government, 2003: The future of primary care: an action plan for primary care in Wales. Cardiff: WAG; 2003.

3. National Assembly for Wales: Improving health in Wales - a plan for the NHS and its partners. Cardiff: Welsh Assembly Government; 200I.

4. Welsh Assembly Government: The future of primary care - an action plan for primary care in Wales. Cardiff: Welsh Assembly Government; 2002.

5. Murray M, Tantau C: Must patients wait? Joint Commission Journal on Quality Improvement 1998, 24:423-5.

6. Warrender TS: Promoting advanced access in primary care. Chichester: Aeneas Press; 2002.

7. Murray M, Berwick DM: Advanced Access. Reducing waiting and delays in primary care. JAMA 2003, 289:1035-1040.

8. Goodall S, Montgomery A, Banks J, Salisbury C, Sampson F, Pickin M: Implementation of Advanced Access in general practice: postal survey of practices. British Journal of General Practice 2006, 56:918-923.

9. White $S$, Jones $M$ : Impact of advanced access. British Journal of General Practice 2004, 54:622.

10. Pascoe SW, Neal RD, Allgar VL: Open access versus bookable appointment systems: survey of patients attending appointments with general practitioners. Br J Gen Pract 2004, 54:367-369.

II. Ahluwalia S, Offredy M: A qualitative study of the impact of the implementation of advanced access in primary healthcare on the working lives of general practice staff. BMC Fam Pract 2005, 6:39. 
12. Salisbury C, Goodall S, Montgomery AA, Pickin DM, Edwards S, Sampson F, et al:: Does Advanced Access improve access to primary health care? Questionnaire survey of patients. British Journal of General Practice 2007, 57:615-62I.

13. Salisbury C, Montgomery AA, Simons L, Sampson F, Edwards S, Baxter $\mathrm{H}$, et al:: Impact of Advanced Access on access, workload, and continuity: controlled before-and-after and simulatedpatient study. British Journal of General Practice 2007, 57:608-6I4.

14. Department of Health: The new GMS contract 2003: investing in general practice. London: BMA/NHS Federation; 2003.

15. Meade JG, Brown JS: Improving access for patients - a practice manager questionnaire. BMC Family Practice 2006, 7:37.

16. Edwards P, Roberts I, Clarke M, DiGuiseppi C, Pratap S, Wentz R, Kwan I, Cooper R: Methods to increase response rates to postal questionnaires. The Cochrane Database of Methodology Reviews 4. Chichester: John Wiley \& Sons; 2003.

Publish with Bio Med Central and every scientist can read your work free of charge

"BioMed Central will be the most significant development for disseminating the results of biomedical research in our lifetime. "

Sir Paul Nurse, Cancer Research UK

Your research papers will be:

- available free of charge to the entire biomedical community

- peer reviewed and published immediately upon acceptance

- cited in PubMed and archived on PubMed Central

- yours - you keep the copyright

Submit your manuscript here:

http://www.biomedcentral.com/info/publishing_adv.asp 